\title{
Diet starch concentration and starch fermentability affect energy intake and energy balance of cows in the early postpartum period
}

\author{
R. I. Albornoz, ${ }^{1 *}$ K. J. Harvatine, ${ }^{2}$ and M. S. Allen ${ }^{1} \dagger$ \\ ${ }^{1}$ Department of Animal Science, Michigan State University, East Lansing 48824 \\ ${ }^{2}$ Department of Animal Science, The Pennsylvania State University, University Park 16802
}

\begin{abstract}
Our objective was to evaluate the effects of diet starch concentration and fermentability on energy intake and energy balance during the early postpartum (PP) period. Fifty-two multiparous Holstein cows were used in a randomized block design experiment with a $2 \times 2$ factorial arrangement of treatments. Treatment rations were formulated to $22 \%$ or $28 \%$ starch concentration (LS and HS, respectively) with dry ground corn (DGC) or high moisture corn (HMC) as the primary starch source. Rations were formulated for $22 \%$ forage neutral detergent fiber (NDF) and $17 \%$ crude protein and fed from 1 to 23 d PP. Starch concentration was adjusted by altering concentrations of corn grain and soyhulls. Dry matter intake and milk yield were measured daily, and milk components, milk composition, body condition score (BCS), body weight (BW), and back fat thickness (BFT) were measured weekly. Feeds and refusals as well as fecal samples were collected, and digestibility was determined weekly. High moisture corn (HMC) decreased dry matter and net energy $\left(\mathrm{NE}_{\mathrm{L}}\right)$ intakes compared with DGC more when included in an HS diet $(3.9 \mathrm{~kg} / \mathrm{d}$ and $3.2 \mathrm{Mcal} / \mathrm{d})$ than in an LS diet $(0.9 \mathrm{~kg} / \mathrm{d}$ and $0.6 \mathrm{Mcal} / \mathrm{d}$ ). The HMC treatment decreased NDF digestibility 3.7 percentage units compared with DGC when included in the HS diet but had little effect when included in an LS diet. Compared with DGC, HMC increased weekly BW and BFT loss when included in an HS diet ( -34.7 vs. $-8.4 \mathrm{~kg} / \mathrm{wk}$ and -0.12 vs. -0.10 $\mathrm{cm} / \mathrm{wk}$ ) and decreased weekly BW loss but increased weekly BFT loss when included in an LS diet $(-18.9$ vs. $-21.4 \mathrm{~kg} / \mathrm{wk}$ and -0.11 vs. $-0.02 \mathrm{~cm} /$ wk). Weekly BCS loss increased for HMC compared with DGC ( -0.33 vs. -0.23 unit/wk). High moisture corn also decreased milk $\mathrm{NE}_{\mathrm{L}}$ output compared with DGC (28.2
\end{abstract}

Received September 1, 2018.

Accepted February 17, 2019.

*Current address: Agriculture Victoria Research, 1301 Hazeldean Road, Ellinbank, Victoria 3821, Australia.

$\dagger$ Corresponding author: allenm@msu.edu vs. $31 \mathrm{Mcal} / \mathrm{d}$ ), but had little effect on energy balance, which was improved by HS compared with LS $(-14.7$ vs. $-16.8 \mathrm{Mcal} / \mathrm{d})$. Over time, concentrations of milk de novo fatty acids ( $<16$ carbons) increased and concentration of milk preformed fatty acids ( $>16$ carbons) decreased for all treatments, but yields of both sources as well as yield of mixed fatty acids (C16:0 plus C16:1 cis-9 and iso-C16:0) decreased over time with increased SF. Feeding HMC decreased energy intake and milk energy output, but it had little effect on energy balance during the early PP period.

Key words: postpartum period, starch concentration, fermentability, energy balance

\section{INTRODUCTION}

The early postpartum (PP) period is characterized by depressed feed intake and increased nutrient demand to sustain milk production and other bodily functions. Decreased energy intake and increased energy output results in negative energy balance, predisposing cows to health disorders and decreased performance. Increasing energy density of the diet by increasing the concentration of starch, which provides glucose and glucose precursors, is a strategy commonly used to increase energy intake in dairy cows. However, diet starch concentration (SC) and starch fermentability (SF) affect cow production and metabolism differently depending on stage of lactation (Oba and Allen, 2003a; Albornoz and Allen, 2018), and these effects are likely associated with cow's blood insulin concentration and insulin response to glucose (Bradford and Allen, 2007; Allen et al., 2009), degree of lipolysis (Piantoni et al., 2015), and rate of propionate production and absorption (Oba and Allen, 2003b; Maldini and Allen, 2018). We demonstrated that feeding a highly fermentable starch source (e.g., high moisture corn, HMC) depressed DMI and milk production compared with a starch source of moderate ruminal fermentability (e.g., dry ground corn, DGC) during the early PP period, and effects were exacerbated when included in a high starch (HS) diet with the same forage NDF (fNDF) 
concentration as a low starch (LS) diets (Albornoz and Allen, 2018). Likely, the more fermentable starch source increased propionate production and absorption, which can increase oxidation of fuels in the liver that triggers a satiety signal consistent with the hepatic oxidation theory (Allen et al., 2009).

Feeding HS diets was previously shown to increase concentrations of blood plasma glucose and insulin (Oba and Allen, 2003a; McCarthy et al., 2015b). However, the decrease in plasma insulin concentration and insulin sensitivity in adipose tissue during the peripartum period promotes lipolysis (Drackley, 1999), which can exacerbate hypophagic effects of propionate (Piantoni et al., 2015).

Increasing diet SC or SF can affect rumen microbial populations and rumen $\mathrm{pH}$. Reduced ruminal $\mathrm{pH}$ can decrease fiber digestibility and increase production of trans fatty acid (FA) intermediates that could increase the risk for diet-induced milk fat depression (Jenkins et al., 2003; Lascano et al., 2016). The combined effect of diet SC and SF on energy intake and energy balance and the risk for milk fat depression during the early PP period have not been investigated.

Our objective was to evaluate the combined effects of diet SC and SF for cows in the early PP period on energy intake, energy balance, glucose metabolism, and milk FA composition. The starch treatments were corn grain harvested as high moisture (high ruminal fermentability) or dry (moderate ruminal fermentability). Starch concentration of diets was adjusted by altering concentrations of corn grain and soyhulls, keeping fNDF and the filling effect of diets constant. We hypothesized that rations with highly fermentable starch will decrease energy intake and affect metabolism involved in energy conservation by cows during the early PP period compared with rations with moderate starch fermentability, and effects will be greater for diets with greater starch concentration.

\section{MATERIALS AND METHODS}

\section{Animal Care}

This study was conducted from February 1 to November 15, 2015, at the Dairy Cattle Research and Teaching Center at Michigan State University, with all experimental procedures approved by the Michigan State University Institutional Animal Care and Use Committee (East Lansing, MI; AUF 11/13-254-00). Additional descriptions of experimental procedures and results have been included in our companion paper (Albornoz and Allen, 2018). Cows were housed individually in tiestalls, allowing for daily records of feed offered and refused, and fed once a day $(0800 \mathrm{~h})$ at
$115 \%$ of expected intake and milked in a parlor twice a day $(0400$ and $1430 \mathrm{~h})$. All cows were in apparent good health at the beginning of the experiment and standard farm health and reproductive protocols were maintained during this study. Signs for ketosis (e.g., depressed feed intake and milk yield and change in normal behavior) were monitored daily and diagnosis was aided with the use of a urine ketone test (Ketostix, Bayern Corp., Elkhart, IN). Confirmed cases were administered $300 \mathrm{~mL}$ of propylene glycol for 3 to $5 \mathrm{~d}$.

\section{Experimental Design and Treatments}

Fifty-two multiparous Holstein cows were used in a completely randomized block design experiment with 2 $\times 2$ factorial arrangement of treatments with 13 cows per treatment. Blocking criteria included BCS observed within 1 wk before expected calving date (up to 1-unit difference within block using a 5-point scale, where $1=$ thin and 5 = fat; Wildman et al., 1982), previous lactation 305-d mature-equivalent milk production (up to $5,000-\mathrm{kg}$ difference within block) and calving date (up to $60 \mathrm{~d}$ within block). A common close-up diet was fed from $21 \mathrm{~d}$ before expected calving date until calving. This diet contained corn silage, mature grass hay, dry ground corn, soybean meal, SoyChlor (West Central Soy, Ralston, IA), and a mineral and vitamin mix, and it was formulated to contain $42.5 \% \mathrm{NDF}, 38.3 \% \mathrm{fNDF}$, $21.5 \%$ starch, and $13.5 \% \mathrm{CP}$.

Treatments included diet SC (22\%, LS; $28 \%$, HS) and diet SF (DGC or HMC). At calving, cows within each block were randomly assigned to 1 of the 4 diet treatment combinations (LS-DGC, LS-HMC, HS-DGC, HS-HMC). Dry ground corn grain was stored in a covered gravity wagon and HMC was ground and ensiled in a bag (Ag-Bag Plastic, Cottage Grove, MN) for at least $4 \mathrm{mo}$ after harvest before utilization. Differences in $\mathrm{SF}$ were confirmed by 7-h in vitro starch digestibility analysis (Goering and Van Soest, 1970) before and throughout the experiment (44.1 and $61.9 \%$ for DGC and HMC, respectively; Albornoz and Allen, 2018). Starch concentration of treatment diets was adjusted by partially replacing the main starch source with soyhulls to maintain the same fNDF concentration across treatment diets. Treatment diets contained alfalfa silage, grass hay, corn grain treatments, soyhulls, soybean meal, minerals, and vitamins and were formulated to $17 \% \mathrm{CP}$ and $22 \% \mathrm{fNDF}$. Cows received their respective diets beginning at day of calving if they calved before feeding time $(0800 \mathrm{~h})$ or at the following morning's feeding until 23 d PP. Dry matter concentration of fermented feeds was determined twice per week throughout the experiment and diets were adjusted accordingly. All rations were formulated to meet or 
Table 1. Ingredient and nutrient composition of treatment diets ${ }^{1}$

\begin{tabular}{|c|c|c|c|c|}
\hline \multirow[b]{2}{*}{ Item } & \multicolumn{2}{|c|}{ LS } & \multicolumn{2}{|c|}{ HS } \\
\hline & DGC & $\mathrm{HMC}$ & DGC & $\mathrm{HMC}$ \\
\hline \multicolumn{5}{|l|}{ Ingredient, $\%$ of DM } \\
\hline Alfalfa silage & 37.0 & 37.1 & 37.7 & 37.0 \\
\hline Grass hay & 8.25 & 8.35 & 8.35 & 8.21 \\
\hline DGC & 27.5 & - & 35.4 & - \\
\hline HMC & - & 28.1 & - & 36.2 \\
\hline Soyhulls & 11.0 & 11.0 & 1.87 & 2.18 \\
\hline Soybean meal & 11.7 & 11.1 & 12.2 & 12.4 \\
\hline Mineral-vitamin $\operatorname{mix}^{2}$ & 2.02 & 2.02 & 2.02 & 2.02 \\
\hline Limestone & 0.55 & 0.55 & 0.55 & 0.55 \\
\hline Sodium bicarbonate & 0.95 & 0.95 & 0.95 & 0.95 \\
\hline Dicalcium phosphate & 0.95 & 0.95 & 0.95 & 0.95 \\
\hline \multicolumn{5}{|c|}{ Nutrient composition, \% of DM } \\
\hline DM & 58.4 & 55.2 & 59.2 & 53.1 \\
\hline $\mathrm{OM}$ & 89.5 & 89.4 & 89.8 & 89.6 \\
\hline NDF & 33.0 & 33.0 & 28.3 & 27.6 \\
\hline Forage NDF & 22.4 & 22.8 & 22.6 & 22.2 \\
\hline $\mathrm{CP}$ & 17.2 & 16.7 & 17.3 & 16.9 \\
\hline Starch & 21.4 & 21.9 & 27.1 & 27.8 \\
\hline Ash & 10.5 & 10.5 & 10.2 & 10.3 \\
\hline Gross energy, Mcal/kg & 4.21 & 4.21 & 4.25 & 4.25 \\
\hline
\end{tabular}

exceed the cows' predicted requirements for protein, minerals, and vitamins according to NRC (2001), and ingredient and nutrient composition of treatment diets is reported in Table 1.

\section{Data and Sample Collection}

Feed offered, orts, and milk yield were recorded on a daily basis throughout the experiment. Samples and measurements were collected or recorded on the same day of the week $\pm 3 \mathrm{~d}$ relative to expected calving date prepartum or relative to day of calving during the PP period. Back fat thickness (BFT), BCS, BW, feed ingredients, fecal samples, and PM milk samples were collected on the same day of the week $(5,12,19 \mathrm{~d} \mathrm{PP})$, with a.m. milk, fecal, and orts samples collected the following morning. Also, an additional measurement of BFT was performed within a week before calving and $\mathrm{BCS}$ and $\mathrm{BW}$ were determined at calving to determine the change in those variables during the first week PP. A glucose tolerance test (GTT) was performed on d 14 PP according to Bradford and Allen (2007).

Representative samples $(0.5 \mathrm{~kg})$ of feed ingredients and orts from each cow were collected weekly throughout the experiment and stored at $-20^{\circ} \mathrm{C}$ for later analysis of DM and nutrient composition. Fecal samples $(0.5 \mathrm{~kg})$ were collected from the rectum every $8 \mathrm{~h}$ of a 24 -h period to account for diurnal variation. Feces were stored in sealed plastic cups at $-20^{\circ} \mathrm{C}$ until dried. Milk samples were collected weekly at each milking and stored with preservative (Bronopol, D\&F Control Systems, San Ramos, CA) at $4^{\circ} \mathrm{C}$ for component and SCC analysis (Universal Lab Services, East Lansing, MI). An additional milk sample was collected without preservative and stored at $-20^{\circ} \mathrm{C}$ for milk FA analysis. Body condition was scored by 3 trained investigators on a 5-point scale, as described by Wildman et al. (1982). Subcutaneous cross-section measurements of BFT were performed on the right side of the cow between the 12th and 13th rib by ultrasonography (Aloka SSD-500V monitor and UST-5044 3.5-MHz probe, Aloka Co. Ltd., Tokyo, Japan). Back fat thickness was determined by performing an average of 2 measurements that were within $0.1 \mathrm{~cm}$ difference.

\section{Sample Analysis}

Feed ingredients, orts, and fecal samples were dried in a $55^{\circ} \mathrm{C}$ forced-air oven for $72 \mathrm{~h}$, analyzed for DM concentration, and ground with a Wiley mill (1-mm screen; Arthur H. Thomas Co., Philadelphia, PA). Fecal samples were composited by cow by day on an equal DM basis before analysis. All feed ingredients, orts, and fecal composites for each cow were analyzed by week for DM, ash, NDF, CP, starch, and gross energy concentration. Nutrients were expressed as percentages of 
$\mathrm{DM}$, determined by drying at $105^{\circ} \mathrm{C}$ in a forced-air oven for more than $8 \mathrm{~h}$. Ash concentration was determined after $5 \mathrm{~h}$ of oxidation at $500^{\circ} \mathrm{C}$ in a muffle furnace. Concentration of NDF was determined according to Mertens (2002) and CP was determined according to Hach et al. (1987). The NDF residue after $240 \mathrm{~h}$ of in vitro fermentation (indigestible NDF; Goering and Van Soest, 1970) was used as an internal marker to estimate fecal output and nutrient digestibility (Cochran et al., 1986). Flasks for incubation contained rumen fluid from a nonpregnant dry cow fed dry hay only and were reinoculated at $120 \mathrm{~h}$ to ensure a viable microbial population. Gross energy was determined by bomb calorimetry according to manufacturer's instructions (Parr Instrument Inc., Moline, IL). Starch was measured by gelatinization with sodium hydroxide and subsequent hydrolysis to glucose using an enzymatic method (Karkalas, 1985). Glucose was then measured with a glucose oxidase method (PGO Enzyme Product No. P7119; Sigma Chemical Co., St. Louis, MO) and by determination of absorbance with a microplate reader (SpectraMax 190; Molecular Devices Corp., Sunnyvale, CA).

Intakes of $\mathrm{DE}$ and $\mathrm{ME}$ were calculated according to NRC (2001):

DE intake $=$ gross energy intake $(\mathrm{Mcal} / \mathrm{d})$

$\times$ gross energy digestibility,

$\mathrm{ME}$ intake $=[1.01 \times(\mathrm{DE}-0.45)] \times \mathrm{DMI}(\mathrm{kg} / \mathrm{d})$,

$\mathrm{NE}_{\mathrm{L}}$ intake $=[(0.703 \times \mathrm{ME})-0.19] \times \mathrm{DMI}(\mathrm{kg} / \mathrm{d})$.

Energy balance was determined according to NRC (2001):

$\mathrm{NE}_{\mathrm{L}}$ balance $(\mathrm{Mcal} / \mathrm{d})=\mathrm{NE}_{\mathrm{L}}$ intake $(\mathrm{Mcal} / \mathrm{d})$

- NE maintenance (Mcal/d) - $\mathrm{NE}_{\mathrm{L}}(\mathrm{Mcal} / \mathrm{d})$,

where $\mathrm{NE}_{\mathrm{L}}$ intake was calculated from $\mathrm{DE}$ through $\mathrm{ME}$ according to NRC (2001); NE maintenance (Mcal/d) $=0.08 \mathrm{Mcal} / \mathrm{kg} \times \mathrm{BW}(\mathrm{kg})^{0.75}(\mathrm{NRC}, 2001)$; and $\mathrm{NE}_{\mathrm{L}}$ $(\mathrm{Mcal} / \mathrm{d})=$ milk yield $(\mathrm{kg} / \mathrm{d}) \times[($ fat $\% \times 0.0929)+$ (true protein $\% \times 0.0563)+$ (lactose $\% \times 0.0395)]$ (NRC, 2001).

Milk samples were analyzed for fat, true protein, and lactose by mid-infrared spectroscopy (AOAC International, 1997) by the Michigan Herd Improvement Association (Universal Lab Services). Additional PM and AM milk samples for FA analysis were composited by milk yield for each collection day for each cow. Fat cakes from composites were obtained by centrifugation at $1,300 \times g$ for $20 \mathrm{~min}$ at $4^{\circ} \mathrm{C}$ before freezing. Fatty acid profile was determined as described by Rico and Harvatine (2013) with slight modifications. Briefly, lipid extraction was performed according to Hara and Radin (1978) using hexane-isopropanol. Fatty acid methyl esters were prepared by base-catalyzed transmethylation according to Chouinard et al. (1999). Fatty acid methyl esters were quantified by GC using an Agilent 6890A gas chromatograph (Agilent Technologies, Palo Alto, CA) equipped with a fused-silica capillary column (SP-2560, $100 \mathrm{~m} \times 0.25 \mathrm{~mm}$ i.d. with $0.2-\mu \mathrm{m}$ film thickness; Supelco Inc., Bellefonte, PA) and a flame-ionization detector with hydrogen as the carrier gas. Initial oven temperature was $80^{\circ} \mathrm{C}$, which was increased by $2^{\circ} \mathrm{C} / \mathrm{min}$ to $190^{\circ} \mathrm{C}$ and held for 15 min. Inlet and detector temperatures were $250^{\circ} \mathrm{C}$ with a 100:1 split ratio. Constant gas flows were $1 \mathrm{~mL} / \mathrm{min}$ for hydrogen carrier, $25 \mathrm{~mL} / \mathrm{min}$ for detector hydrogen, $400 \mathrm{~mL} / \mathrm{min}$ for detector airflow, and $40 \mathrm{~mL} / \mathrm{min}$ for detector nitrogen plus carrier. Fatty acid peaks were identified using FAME standards (GLC 461, GLC 780, and pure CLA trans-10,cis-12 and CLA cis-9,trans-11, NuChek Prep Inc., Elysian, MN; Bacterial Acid Methyl Ester Mix, 47080-U, Sigma-Aldrich; and GLC 110 mixture, Matreya LLC, State College, PA). Recovery of individual FA were determined using an equal weight reference standard (GLC 461; NuChek Prep Inc.). Correction factors for individual FA and calculation of milk FA yield were carried out as described by Rico and Harvatine (2013).

Plasma samples from GTT were analyzed for glucose using a glucose oxidase method (PGO Enzyme Product No. P7119; Sigma Chemical Co.) and insulin with a commercial kit (Coat-A-Count RIA kit; Siemens Healthcare Diagnostics, Deerfield, IL). Area under the curve for glucose and insulin was calculated using the trapezoidal rule.

\section{Statistical Analysis}

All data were analyzed using the Fit Model procedure of JMP Pro (version 13, SAS Institute, Cary, NC) according to the following model:

$$
\begin{gathered}
\mathrm{Y}_{\mathrm{ijosf}}=\mu+\mathrm{B}_{\mathrm{i}}+\mathrm{C}\left(\mathrm{B}_{\mathrm{i}}\right)_{\mathrm{j}}+\mathrm{J}+\mathrm{O}_{\mathrm{o}}+\mathrm{S}_{\mathrm{s}}+\mathrm{F}_{\mathrm{f}}+\mathrm{S}_{\mathrm{s}} \mathrm{F}_{\mathrm{f}} \\
+\mathrm{T}+\mathrm{S}_{\mathrm{s}} \mathrm{T}+\mathrm{F}_{\mathrm{f}} \mathrm{T}+\mathrm{S}_{\mathrm{s}} \mathrm{F}_{\mathrm{f}} \mathrm{T}+\mathrm{e}_{\mathrm{ijosf}},
\end{gathered}
$$

where $\mathrm{Y}_{\mathrm{ijosf}}=$ response variable; $\mu=$ overall mean; $\mathrm{B}_{\mathrm{i}}=$ random effect of block ( $\mathrm{i}=1$ to 13$) ; \mathrm{C}\left(\mathrm{B}_{\mathrm{i}}\right)_{\mathrm{j}}=$ random effect of cow ( $\mathrm{j}=1$ to 4 ) within block; $\mathrm{J}=$ random effect of Julian date; $\mathrm{O}_{\mathrm{o}}=$ days offset from fixed weekly sampling day $(\mathrm{o}=-3$ to +3$) ; \mathrm{S}_{\mathrm{s}}=$ fixed effect of $\mathrm{SC}$ ( $\mathrm{s}=1$ to 2$) ; \mathrm{F}_{\mathrm{f}}=$ fixed effect of $\mathrm{SF}$ ( $\mathrm{f}=1$ to 2 ); $\mathrm{S}_{\mathrm{s}} \mathrm{F}_{\mathrm{f}}$ 
$=$ interaction between $\mathrm{SC}$ and $\mathrm{SF} ; \mathrm{T}=$ fixed effect of sampling day $\mathrm{PP} ; \mathrm{S}_{\mathrm{s}} \mathrm{T}=$ interaction between $\mathrm{SC}$ and day $\mathrm{PP} ; \mathrm{F}_{\mathrm{f}} \mathrm{T}=$ interaction between $\mathrm{SF}$ and day $\mathrm{PP}$; $\mathrm{S}_{\mathrm{s}} \mathrm{F}_{\mathrm{f}} \mathrm{T}=$ interaction between $\mathrm{SC}, \mathrm{SF}$, and day $\mathrm{PP}$; and $\mathrm{e}_{\mathrm{ijosf}}=$ residual error.

Day PP was included in the model as continuous measure and linear and quadratic interactions between main effects and sampling day PP were evaluated. Interactions with time were removed from the model for GTT data analysis, and when they were nonsignificant, a reduced model was used to determine treatment effects. However, all interactions were included in the tables for informational purposes. Normality of the residuals was checked with normal probability and box plots and homogeneity of variances with plots of residuals versus predicted values. Goodness of normal fit was also tested with Shapiro-Wilk. Because of storage issues with milk samples for FA analysis for the first 3 blocks (12 cows), this analysis was performed on the subsequent 10 blocks (40 cows). All cows were included for the analysis of all other variables. Treatment effects were declared significant at $P<0.05$ and tendencies at $P<0.10$. Interactions were declared significant at $P<$ 0.10 and tendencies at $P<0.15$.

\section{RESULTS}

\section{Digestibility and Energy Balance}

Dry matter, NDF, CP, and starch intakes increased over time for both starch sources, but more for DGC compared with HMC throughout the treatment period $(P=0.12, P=0.02, P=0.03$, and $P=0.04$, linear, respectively; Table 2). The LS diets decreased starch intake $(1.1 \mathrm{~kg} / \mathrm{d})$ and increased NDF intake $(0.88$ $\mathrm{kg} / \mathrm{d})$ compared with HS diets $(P<0.01)$. The HMC treatment decreased daily intake of DM, NDF, CP, and starch compared with DGC $(P<0.02$ for all $)$, but the decrease was greater when included in the HS (3.9, $1.06,0.65$, and $0.89 \mathrm{~kg} / \mathrm{d}$, respectively) than the LS diet $(0.9,0.20,0.18$, and $0.15 \mathrm{~kg} / \mathrm{d}$; interaction, $P=0.07, P$ $=0.11, P=0.12$, and $P=0.10$, respectively).

The HS treatment increased total-tract digestibility of DM, OM, and gross energy by $2.5,2.3$, and 2.4 percentage units compared with LS, respectively $(P<$ 0.01; Table 2). The HMC treatment decreased NDF digestibility by 3.7 percentage units compared with DGC when included in the HS diet but had little effect when included in the LS diet (interaction $P=0.10$ ).

Table 2. Effects of diet starch concentration (SC) and starch fermentability (SF) on DMI, body reserves, apparent total-tract digestibility, and energy balance ${ }^{1}$

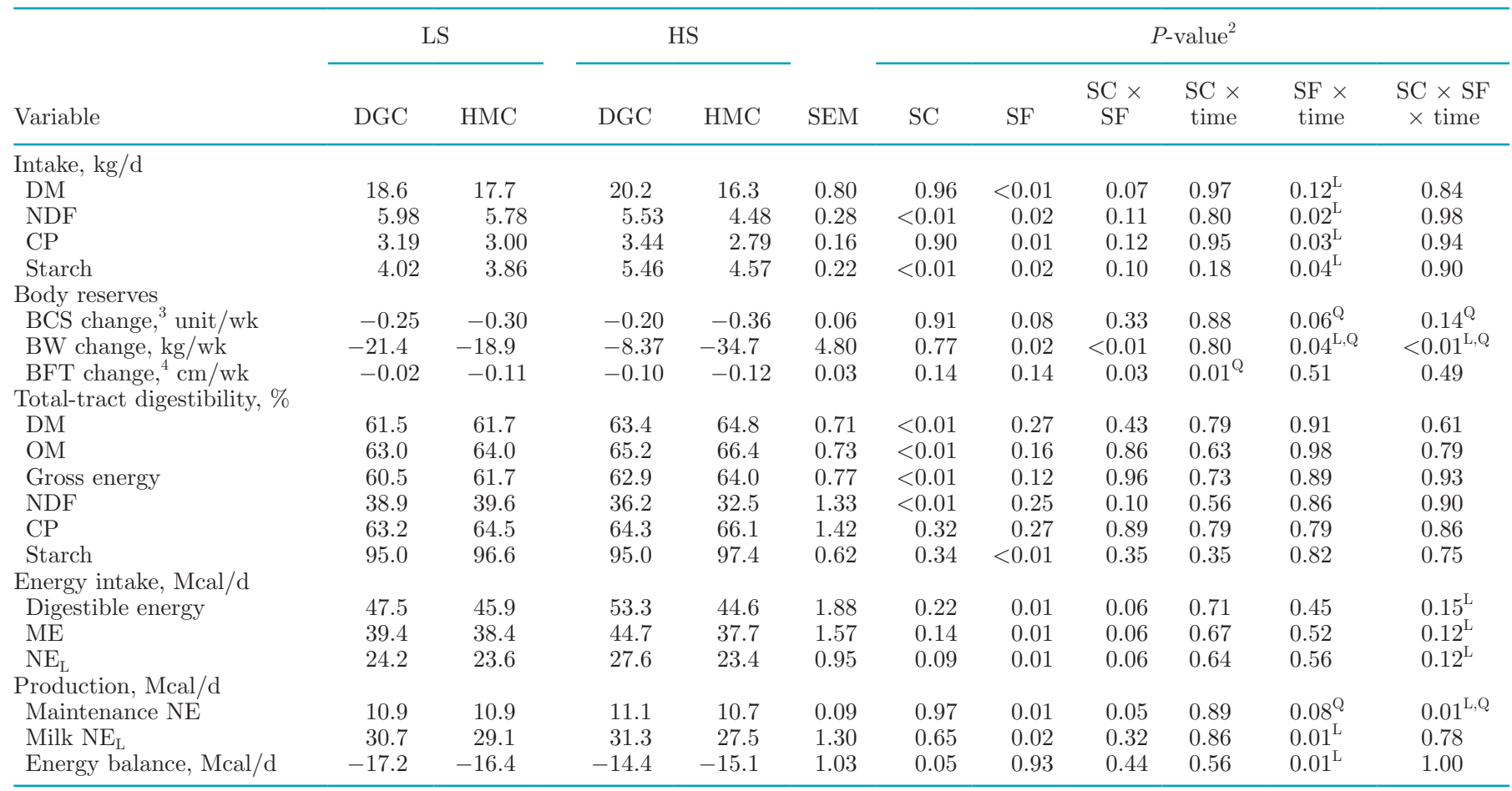

${ }^{1} \mathrm{LS}=$ low starch $(22 \%$ starch $) ; \mathrm{HS}=$ high starch $(28 \%$ starch $)$; DGC = dry ground corn; HMC = high moisture corn.

${ }^{2}$ Time $=$ day postpartum. Polynomial interactions are identified with superscripts: $\mathrm{L}=$ linear and $\mathrm{Q}=$ quadratic.

${ }^{3}$ Change represents the difference between final and initial measurement at each week postpartum.

${ }^{4} \mathrm{BFT}=$ back fat thickness. 
High moisture corn increased starch digestibility 2.0 percentage units compared with DGC $(P<0.01)$ but digestibility of $\mathrm{CP}$ was not affected by treatment.

Intakes of $\mathrm{DE}, \mathrm{ME}$, and $\mathrm{NE}_{\mathrm{L}}$ all tended to increase over time, but the rate of increase was less for LS-HMC than the other treatments (interactions; $P=0.15, P$ $=0.12$, and $P=0.12$, all linear, respectively; Figure $1 \mathrm{~A})$. The HMC treatment decreased $\mathrm{DE}, \mathrm{ME}$, and $\mathrm{NE}_{\mathrm{L}}$ intakes compared with DGC $(P<0.01$ for all $)$, and the decrease was greater when included in the HS diet (8.7, 7.0, and $4.2 \mathrm{Mcal} / \mathrm{d}$, respectively) than the LS $\operatorname{diet}(1.6,1.0$, and $0.6 \mathrm{Mcal} / \mathrm{d}$, respectively; all interactions $P=0.06)$. The HMC treatment decreased the energy required for maintenance compared with DGC in the HS diet (10.7 vs. $11.1 \mathrm{Mcal} / \mathrm{d})$, but did not differ between SF treatments when included in the LS $\operatorname{diet}(10.9 \mathrm{Mcal} / \mathrm{d}$; interaction $P=0.05)$. Over time, all treatments decreased energy required for maintenance following change in BW, but HS-HMC had a more pronounced decrease during the second week PP compared with the rest of the treatments $(P=0.01$, quadratic). Milk energy output increased over time for DGC but decreased for HMC $(P=0.01$, linear; Figure 1B), and HMC decreased milk energy output 2.7 Mcal/d compared with DGC over the treatment period. Energy balance was negative for all treatments during the treatment period, but HS improved energy balance compared with LS ( -14.7 vs. $-16.8, P=0.05)$, and HMC decreased energy balance during the first week PP and increased thereafter compared with DGC $(P=0.01$, linear; Figure 1C).

\section{Body Reserves}

Body condition score decreased over each week, but the pattern of loss varied by treatment, with a greater loss for the HS-HMC and smaller loss for the HS-DGC treatments compared with the other treatments until the second week PP and then smaller loss for the HSHMC and greater loss for HS-DGC compared with the other treatments for the remainder of the treatment period $(P=0.14$, quadratic, Table 2). Overall, HMC tended to increase weekly BCS loss compared with DGC $(P=0.08)$, with both treatments reaching similar values by the third week PP $(P=0.06$, quadratic). Body weight also decreased each week through the treatment period, with patterns among treatments over time similar to those for BCS. The HS-HMC treatment combination increased and HS-DGC decreased BW loss compared with the other treatments until wk 2, but HS-HMC decreased and HS-DGC increased BW loss compared with the other treatments for the remainder of the treatment period $(P<0.01$, quadratic $)$. Over the treatment period, HMC increased BW loss com-

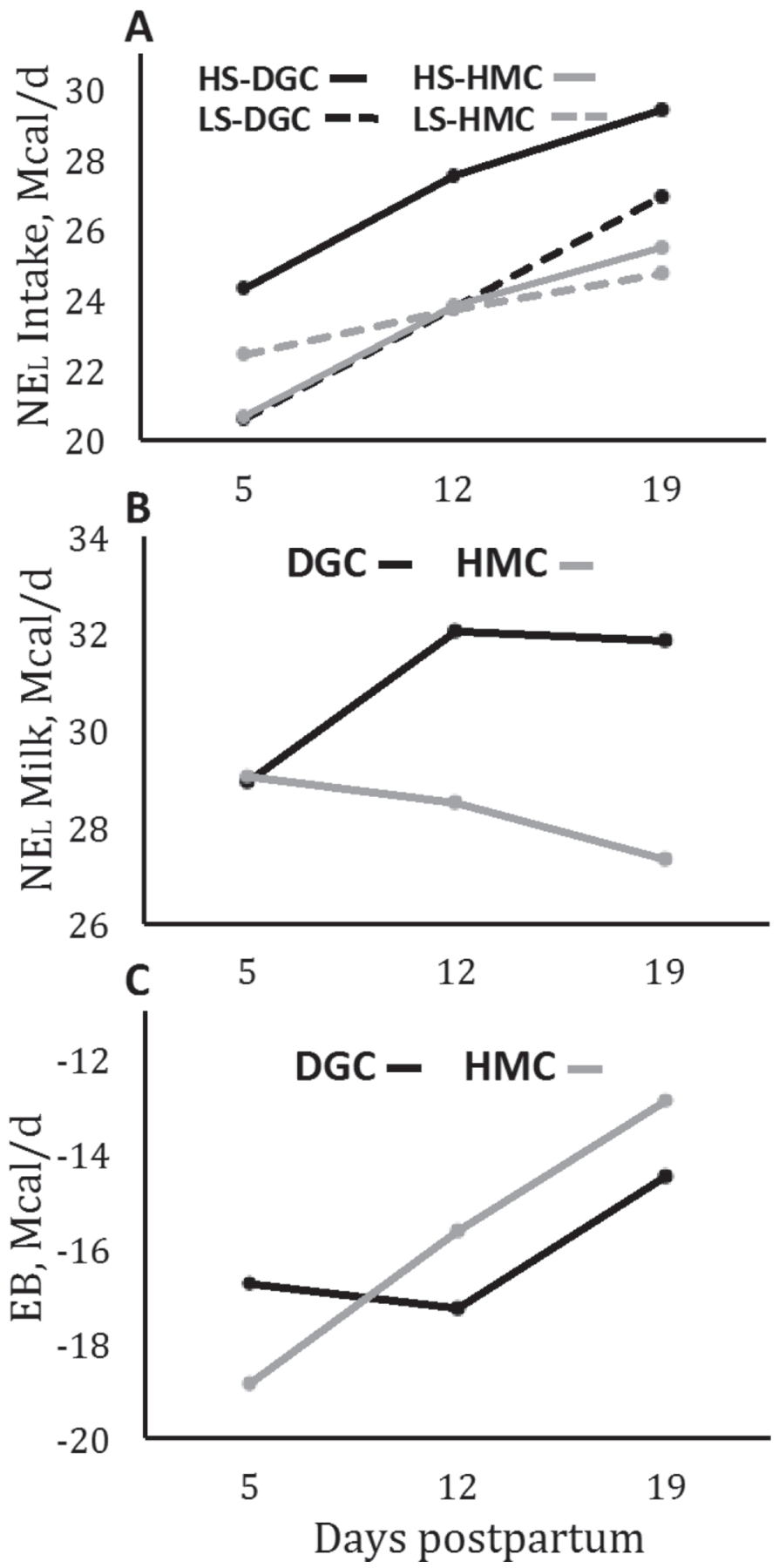

Figure 1. Effects of diet starch concentration (SC) and fermentability (SF) on (A) $\mathrm{NE}_{\mathrm{L}}$ intake and effects of diet $\mathrm{SF}$ on (B) milk $\mathrm{NE}_{\mathrm{L}}$ and $(\mathrm{C})$ energy balance (EB). For (A), treatments are $28 \%$ starch with dry ground corn (HS-DGC), $22 \%$ starch with dry ground corn (LS-DGC), $28 \%$ starch with high moisture corn (HS-HMC), and $22 \%$ starch with high moisture corn (LS-HMC). For (B) and (C), treatments are dry ground corn (DGC) and high moisture corn (HMC). Interactions among $\mathrm{SC}, \mathrm{SF}$, and day postpartum are represented for $\mathrm{NE}_{\mathrm{L}}$ intake $(P=0.12$, linear $)$ and interactions between $\mathrm{SF}$ and day postpartum for $(\mathrm{B})$ milk $\mathrm{NE}_{\mathrm{L}}(P=0.01$, linear $)$ and $(\mathrm{C}) \mathrm{EB}(P=$ 0.01 , linear). 
pared with DGC for HS ( -34.7 vs. $-8.4 \mathrm{~kg} / \mathrm{wk}$ ) but decreased BW loss compared with DGC for LS $(-18.9$ vs. $-21.4 \mathrm{~kg} / \mathrm{wk} ; P<0.01)$, with the greatest difference at the second week $(P=0.04$, quadratic $)$. Back fat thickness decreased for all treatments during the treatment period but HMC increased BFT loss more compared with DGC for LS ( -0.11 vs. $-0.02 \mathrm{~cm} / \mathrm{wk})$ than HS ( -0.12 vs. $-0.10 ; P=0.03$; Table 2$)$ and HS increased loss more during the second week PP, with similar loss rate during the first and third week PP compared with LS treatments ( $P=0.01$, quadratic).

\section{Glucose Tolerance Test}

Starch concentration and SF interacted to affect baseline (pre-glucose infusion) glucose concentration, with HMC increasing glucose concentration compared with DGC for HS (47.7 vs. $42.1 \mathrm{mg} / \mathrm{dL}$ ) and decreasing glucose concentration for LS (40.7 vs. $44.2 \mathrm{mg} / \mathrm{dL}, P=$ 0.02 ; Table 3$)$. However, treatment did not affect maximum glucose concentrations or time required to reach it. The HMC treatment tended to increase the rate of increase in glucose concentration from 10.2 to $11.0 \mathrm{mg} /$ $\mathrm{dL}$ per minute $(P=0.09)$ compared with DGC but the amount of time required to achieve baseline glucose concentrations post infusion and the area under the curve were not different between treatments.

High starch diets increased baseline insulin concentration compared with LS diets (3.59 vs. $2.22 \mu \mathrm{IU} /$ $\mathrm{mL}, P=0.01$ ), but treatment did not affect maximum insulin concentration, time required to reach it, or rate of increase in insulin concentration. The HS treatment reduced the amount of time required to reach baseline insulin concentrations post infusion (88.5 vs. 98.7 min, $P=0.03$ ), but area under the curve did not differ among treatments.

\section{Milk Fatty Acids}

Treatments had no main effects on FA concentrations, but they interacted with each other and time for concentrations of certain individual FA and total de novo, mixed, or preformed milk FA (Table 4). The proportions of mixed FA were not affected by treatments, but treatments interacted with time to affect proportion of de novo FA, which increased over time $(P$ $=0.02$, linear , and proportion of preformed FA, which decreased over time $(P=0.10$, linear; Table 4 ; Supplemental Figure S1; https://doi.org/10.3168/jds.2018 -15634). Overall, SC and SF interacted to affect concentration of $\mathrm{C} 14: 1$ cis-9 and $\mathrm{C} 18: 1$ cis-11, with HMC decreasing their concentrations for LS (0.55 vs. $0.65 \%$ and 1.06 vs. $1.10 \%)$ but increasing their concentrations for HS (0.71 vs. $0.62 \%$ and 1.18 vs. $1.03 \% ; P=0.03$ and $P=0.08$, respectively). Over time, concentration of C14:1 cis-9 and C18:1 cis-11 were higher for LS-DGC and HS-HMC compared with LS-HMC and HS-DGC, with the greatest difference in concentration observed during wk $2 \mathrm{PP}$, with less difference among treatments by the third week PP $(P=0.05$, quadratic and $P=$ 0.06 , linear, respectively). Treatments interacted to affect concentrations of iso-C16:0, C18:1 trans-11, and C18:0, with HMC increasing their concentrations for LS ( 0.21 vs. $0.18 \%, 0.76$ vs. $0.65 \%$, and 13 vs. $11.9 \%)$ but decreasing their concentrations for HS (0.18 vs. $0.21 \%, 0.68$ vs. $0.76 \%$, and 11.7 vs. $12.5 \% ; P=0.10, P$ $=0.03$, and $P=0.02$, respectively). Treatments also interacted with time to affect concentration of iso-C16:0

Table 3. Effects of diet starch concentration (SC) and starch fermentability (SF) on response to glucose tolerance test ${ }^{1}$

\begin{tabular}{|c|c|c|c|c|c|c|c|c|}
\hline Variable & \multicolumn{2}{|c|}{ LS } & \multicolumn{2}{|c|}{ HS } & SEM & \multicolumn{3}{|c|}{$P$-value } \\
\hline Baseline, mg/dL & 44.2 & 40.7 & 42.1 & 47.7 & 2.19 & 0.20 & 0.59 & 0.02 \\
\hline Maximum, mg/dL & 151 & 151 & 148 & 158 & 4.40 & 0.64 & 0.28 & 0.25 \\
\hline Time to maximum, min & 10.8 & 10.0 & 11.5 & 10.0 & 0.86 & 0.66 & 0.19 & 0.66 \\
\hline Rate, $\mathrm{mg} / \mathrm{dL} \times \min$ & 10.4 & 11.0 & 9.92 & 11.0 & 0.48 & 0.69 & 0.09 & 0.65 \\
\hline \multicolumn{9}{|l|}{ Insulin } \\
\hline Baseline, $\mu \mathrm{IU} / \mathrm{mL}$ & 2.34 & 2.10 & 3.73 & 3.45 & 0.59 & 0.01 & 0.61 & 0.98 \\
\hline Maximum, $\mu \mathrm{IU} / \mathrm{mL}$ & 61.5 & 65.1 & 69.7 & 72.5 & 6.23 & 0.21 & 0.61 & 0.95 \\
\hline Time to maximum, min & 13.8 & 12.5 & 13.1 & 15.4 & 1.36 & 0.46 & 0.73 & 0.21 \\
\hline Rate, $\mu \mathrm{IU} / \mathrm{mL} \times \min$ & 4.72 & 5.52 & 5.68 & 4.87 & 0.64 & 0.82 & 1.00 & 0.23 \\
\hline Time to baseline, $\min$ & 99.2 & 98.1 & 89.2 & 87.7 & 4.87 & 0.03 & 0.77 & 0.96 \\
\hline $\mathrm{AUC}, \mu \mathrm{IU} / \mathrm{mL} \times \min$ & 2,289 & 2,407 & 2,353 & 2,435 & 235 & 0.84 & 0.66 & 0.94 \\
\hline
\end{tabular}

${ }^{1} \mathrm{LS}=$ low starch $(22 \%$ starch $) ; \mathrm{HS}=$ high starch $(28 \%$ starch $)$; DGC = dry ground corn; HMC = high moisture corn.

${ }^{2} \mathrm{AUC}=$ area under the curve, calculated with the trapezoidal rule. 
Table 4. Effects of diet starch concentration (SC) and starch fermentability (SF) on profile and yield of milk fatty acids (FA) ${ }^{1}$

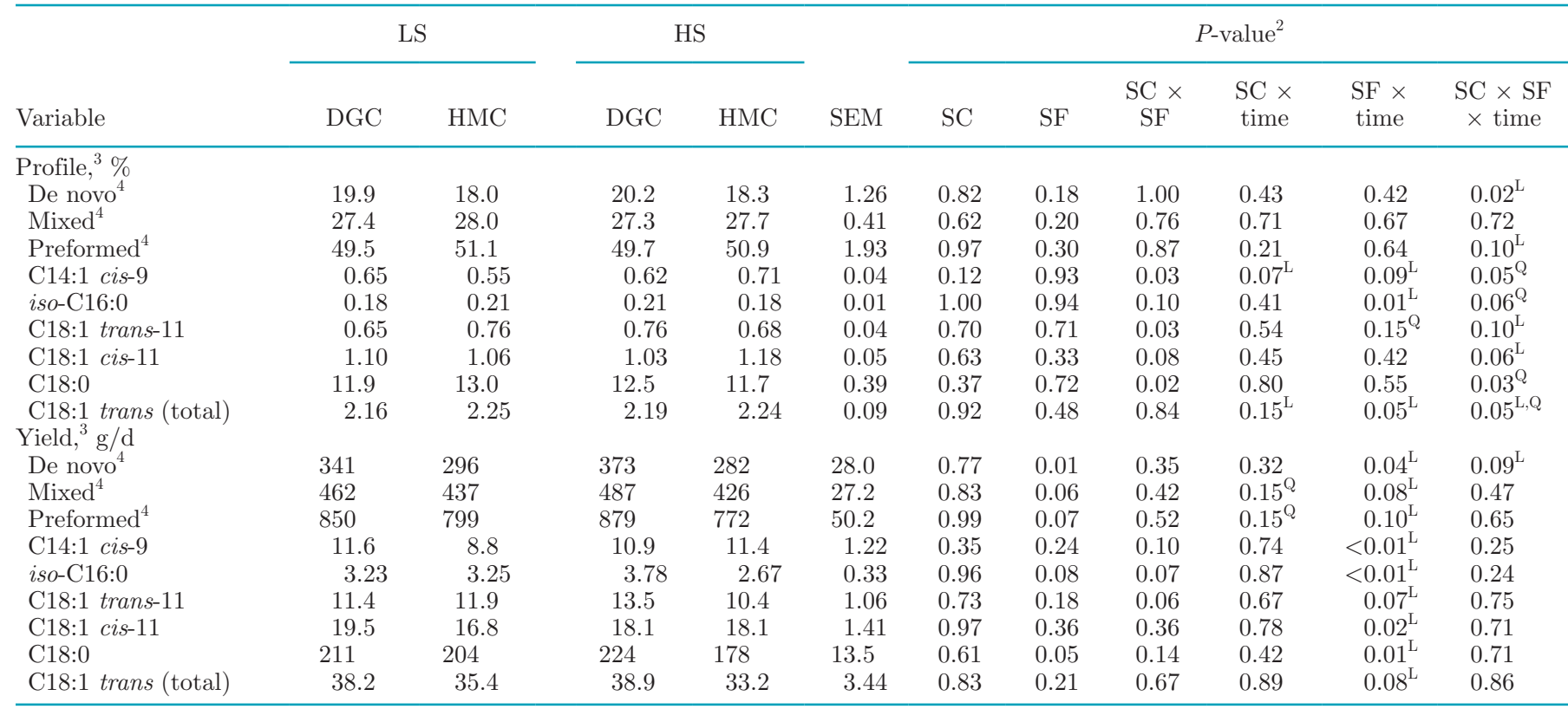

${ }^{1} \mathrm{LS}=$ low $\operatorname{starch}(22 \%$ starch $) ;$ HS $=$ high starch $(28 \%$ starch $) ;$ DGC $=$ dry ground corn; HMC $=$ high moisture corn.

${ }^{2}$ Time = day postpartum. Polynomial interactions are identified with superscripts: $\mathrm{L}=$ linear and $\mathrm{Q}=$ quadratic.

${ }^{3}$ Approximately 64 individual FA were quantified and used for calculations (summation by source).

${ }^{4}$ De novo FA originate from mammary de novo synthesis ( $<16$ carbons), preformed FA originate from extraction from plasma ( $>16$ carbons), and mixed FA originate from both sources (C16:0 plus C16:1 cis-9 and iso-C16:0).

and C18:1 trans-11, which were higher for LS-DGC and HS-HMC compared with LS-HMC and HS-DGC, with less difference among treatments by the third week PP $(P=0.06$, quadratic and $P=0.10$, linear, respectively). Over time, concentration of C18:0 decreased for all treatments, with a greater reduction in concentration by wk 2 PP for LS-DGC and HS-HMC compared with LS-HMC and HS-DGC, with all treatments reaching similar concentration values by the third week $(P=$ 0.03 , quadratic). Treatments did not affect total concentration of $\mathrm{C} 18: 1$ trans $\mathrm{FA}$, but its concentration increased for all treatments and decreased for LS-HMC after the second week PP $(P=0.05$, quadratic $)$.

Milk fat yield was decreased by HMC compared with DGC (190 g/d) and linearly increased over time for DGC and decreased for HMC (Albornoz and Allen, 2018). Accordingly, compared with DGC, HMC decreased yields of de novo FA $(137 \mathrm{~g} / \mathrm{d} ; P=0.01)$ and tended to decrease yields of mixed and preformed FA (86 and $158 \mathrm{~g} / \mathrm{d} ; P=0.06$ and $P=0.07$, respectively), with yields of all sources being greater for DGC compared with HMC after the first week PP $(P=0.09$, linear, $P$ $=0.08$, linear, and $P=0.10$, linear, respectively; Table 4; Supplemental Figure S2; https://doi.org/10.3168/ jds.2018-15634). Similarly, yields of individual FA and total C18:1 trans FA increased for DGC and decreased for HMC after the first week $\mathrm{PP}$ (all $P<0.08$, linear).
However, SC and SF interacted to decrease yield of C14:1 cis-9 for LS-HMC and HS-DGC (8.8 and 10.9 $\mathrm{g} / \mathrm{d}$ ) and increase for LS-DGC and HS-HMC (11.6 and $11.4 \mathrm{~g} / \mathrm{d}$, respectively; $P=0.10$ ). Overall, treatments also interacted to affect yields of iso-C16:0, C18:1 trans-11, and C18:0, with HMC decreasing their yields for HS compared with DGC (2.67 vs. $3.78 \mathrm{~g} / \mathrm{d}, 10.4$ vs. $13.5 \mathrm{~g} / \mathrm{d}$, and 178 vs. $224 \mathrm{~g} / \mathrm{d}$ ) and little difference between HMC and DGC for LS (3.25 vs.3.23 g/d, 11.9 vs. $11.4 \mathrm{~g} / \mathrm{d}$, and 204 vs. $211 \mathrm{~g} / \mathrm{d} ; P=0.07, P$ $=0.06$, and $P=0.14$, respectively). Additional milk FA concentrations and yields are listed as supplemental material in Supplemental Tables S1 and S2 (https://doi .org/10.3168/jds.2018-15634), respectively.

\section{DISCUSSION}

Feeding the highly fermentable starch source HMC depressed DMI compared with DGC, and to a greater extent when included in the HS diet. Intakes of both NDF and starch followed DMI as well as diet composition for the SC treatment, whereas CP intake followed the same trend as DMI. Hypophagic effects of highly fermentable starch sources are likely related to the increased supply of propionate to the liver, which are greater for cows in a lipolytic state, and are consistent with the hepatic oxidation theory (Allen, 2000). 
The HS treatment increased total-tract digestibilities of DM, OM, and gross energy, but decreased NDF digestibility, with a greater decrease for HS-HMC compared with HS-DGC. In contrast, Oba and Allen (2003c) reported no effects of treatment on total-tract NDF digestibility when cows past peak lactation received HS $(32 \%)$ or LS (21\%) diets containing either HMC or DGC. Lower NDF intake by cows in the early PP period compared with early to mid-lactation likely reduces rumen digesta mass and the buffering capacity of the rumen contents (Allen and Piantoni, 2014). Lower NDF intake and higher ruminal starch fermentability for HS-HMC compared with HS-DGC likely diminished ruminal buffering capacity and increased acid production, reducing ruminal $\mathrm{pH}$ and NDF digestibility.

Total-tract starch digestibility was similar for LS and HS treatments but greater for HMC compared with DGC. In contrast, in the study by Oba and Allen (2003c), total-tract starch digestibility was affected differently; SF had no effect, whereas HS increased totaltract starch digestibility compared with LS. However, in that study SC was adjusted by inclusion of fNDF, whereas in the present study fNDF was constant across treatments. Interactions among carbohydrate sources in the rumen likely alter ruminal starch digestibility and ultimately affect total-tract starch digestibility.

Intakes of $\mathrm{DE}, \mathrm{ME}$, and $\mathrm{NE}_{\mathrm{L}}$ followed the same trends as DMI. Rabelo et al. (2003) reported that cows receiving an HS diet (47.2\% NFC) increased DM and energy intake compared with cows receiving an LS diet (41.1\% NFC) during the first $20 \mathrm{~d}$ PP. The starch source in that experiment was dry ground corn and the effect of $\mathrm{SC}$ on energy intake was similar to the DGC treatment but not the HMC treatment in the present experiment. Increasing SC from 22 to $28 \%$ did not increase intakes of DM or energy in our experiment despite the increase in DM digestibility with the HS compared with the LS treatment. Greater BW loss by HS-HMC, particularly during the second week PP, was likely from a combination of decreased DMI and depletion of body reserves as assessed by BCS and BFT measurements, and resulted in lower energy required for maintenance compared with the other treatments. These findings emphasize the importance of the contribution of DMI compared with DM digestibility to maximize energy intake during the early PP period.

The HMC treatments reduced yields of milk, 3.5\% FCM, and ECM (Albornoz and Allen, 2018), resulting in lower milk energy output compared with DGC, particularly during the second and third week PP, which improved energy balance similarly over time. Although HMC decreased DMI compared with DGC, it did not affect energy balance because it also decreased milk energy output. In addition, the increase in BW loss by HMC, likely from decreased gut fill as well as greater mobilization of body reserves, reduced energy required for maintenance compared with DGC. This effect was more pronounced when included in HS, contributing to a reduction in differences in energy balance between $\mathrm{SF}$ treatments. This finding suggests that estimation of energy required for maintenance using the NRC (2001) equation may not reflect the actual shift in energy required to maintain BW by cows during the early PP period. Also, the above-mentioned equation was developed using nonpregnant, nonlactating dairy cows, which likely have different maintenance requirements compared with cows during the early PP period that may require additional energy adjustment for other bodily functions (e.g., recovery of reproductive tract, activated immune system, and growth of gut and splanchnic tissue). Over the whole treatment period, the HS treatment improved energy balance compared with LS overall consistent with the study by McCarthy et al. (2015a), who reported that an HS (25.5\%) diet improved energy balance $5.1 \mathrm{Mcal} / \mathrm{d}$ compared with an LS $(20.9 \%)$ diet during the early PP period but had no effect on DMI, yields of milk, or 3.5\% FCM and caused no change in BW or BCS. These and our results suggest that when SC is increased, energy balance is likely improved, but when feed intake is depressed by highly fermentable starch, decreased milk energy output is the primary mechanism involved in conserving energy.

Over time, HS diets increased glucose and insulin concentrations, with LS diets reaching similar values as HS treatments by the third week PP (Albornoz and Allen, 2018). Similarly, at the time of the GTT (second week PP), HS increased baseline (pre-glucose infusion) plasma insulin concentration compared with LS. In accordance with our findings for DMI, Bradford and Allen (2007) reported that hypophagic effects from HMC were exacerbated for cows with higher mean plasma insulin concentration, possibly because downregulated gluconeogenesis stimulated hepatic oxidation of fuels sooner. Whereas higher insulin concentration is expected to decrease lipolysis and increase lipogenesis in adipose tissue (Bauman, 2000), the opposite was observed for HS-HMC, which increased mobilization of body reserves. In addition, increased mean insulin concentration is expected to clear fuels from the blood faster, but at the time of the GTT, baseline (pre-glucose infusion) plasma glucose concentration increased for HMC compared with DGC when included in an HS diet and decreased for HMC compared with DGC when included in an LS diet. Reasons for this finding are not clear, but the opposite interaction was detected for BHB concentration (Albornoz and Allen, 2018), indicating 
differences in metabolism of fuels between treatments. Following the glucose infusion, HMC had higher rate of increase in glucose concentration compared with DGC, which could be related to a reduced capacity for glucose uptake by tissues in cows that received HMC. Cows during the early PP period have reduced insulin sensitivity (Bell, 1995), and further research to elucidate how SC and SF affect insulin response to glucose and glucose precursors is needed.

Treatments had opposite effects on proportions of milk de novo and preformed FA, but yields of both FA sources as well as mixed FA decreased with greater SF, following the same trend as milk fat yield (Albornoz and Allen, 2018). Higher SF can affect FA biohydrogenation pathways in the rumen and increase synthesis of certain C18:1 isomers considered risk factors for milk fat depression (Mohammed et al., 2010). Whereas abomasal infusion of CLA trans-10,cis-12 causes milk fat depression, it also has been reported to increase abundance of genes related to FA synthesis in adipose tissue (Harvatine et al., 2009b). These effects could increase energy retention and improve energy balance. However, evidence for this possibility is not present in our experiment; treatments did not affect concentration or yield of CLA trans-10,cis-12. Whereas the HS-HMC treatment decreased concentration and yield of C18:1 trans-11, a marker of normal biohydrogenation pathways (Harvatine et al., 2009a), the same shift in concentration was observed for LS-DGC. Further, the HS-HMC treatment decreased milk fat yield but not milk fat concentration compared with the other treatments (Albornoz and Allen, 2018), and cows receiving this treatment as well as those receiving the LS-DGC treatment increased loss of BW and BCS in a similar manner. This evidence indicates that milk fat depression via products of altered FA biohydrogenation pathway likely did not occur in our study and cannot explain the treatment differences observed for change in body reserves.

\section{CONCLUSIONS}

Feeding the highly fermentable starch source HMC decreased DM and energy intake during the early PP period. Negative effects from HMC compared with DGC were increased when included in an HS diet, despite HS diets increasing DM digestibility. However, over time, the decrease in milk energy output by HMC diminished differences in energy balance between starch sources. Whereas the HS-HMC decreased digestibility of NDF compared with HS-DGC possibly a result of decreased rumen $\mathrm{pH}$, no relationship was found between the reduction in milk FA yield or individual milk FA associated with diet-induced milk fat depression.

\section{ACKNOWLEDGMENTS}

We acknowledge financial support for this project by USDA National Research Initiative Competitive Grant no. 2014-67015-21708 to M. S. A., as well as funding from the Fulbright Argentina Program and the Office for International Students and Scholars at Michigan State University to R. I. A. We also thank D. G. Main, R. Longuski, K. Kennedy, L. Gualdron-Duarte, G. Maldini, R. Yair, D. de Souza, and R. West (all from Michigan State University), as well as the staff from the Michigan State University Dairy Cattle Teaching and Research Center (East Lansing) for their assistance with this experiment.

\section{REFERENCES}

Albornoz, R. I., and M. S. Allen. 2018. Highly fermentable starch at different diet starch concentrations decreased feed intake and milk yield of cows in the early postpartum period. J. Dairy Sci. 101:8902-8915.

Allen, M. S. 2000. Effects of diet on short-term regulation of feed intake by lactating dairy cattle. J. Dairy Sci. 83:1598-1624.

Allen, M. S., B. J. Bradford, and M. Oba. 2009. Board invited review: The hepatic oxidation theory of the control of feed intake and its application to ruminants. J. Anim. Sci. 87:3317-3334.

Allen, M. S., and P. Piantoni. 2014. Carbohydrate nutrition: Managing energy intake and partitioning through lactation. Vet. Clin. North Am. Food Anim. Pract. 30:577-597.

AOAC International. 1997. Official Methods of Analysis. 16th ed. AOAC International, Gaithersburg, MD.

Bauman, D. E. 2000. Regulation of nutrient partitioning during lactation: Homeostasis and homeorhesis revisited. Pages 311-328 in Ruminant Physiology, Digestion, Metabolism, Growth and Reproduction. P. B. Cronje, ed. Proc. 9th Int. Symp. Ruminant Physiology. CABI Publishing, New York, NY.

Bell, A. W. 1995. Regulation of organic nutrient metabolism during transition from late pregnancy to early lactation. J. Anim. Sci. 73:2804-2819.

Bradford, B. J., and M. S. Allen. 2007. Depression in feed intake by a highly fermentable diet is related to plasma insulin concentration and insulin response to glucose infusion. J. Dairy Sci. 90:38383845 .

Chouinard, P. Y., L. Corneau, D. M. Barbano, L. E. Metzger, and D. E. Bauman. 1999. Conjugated linoleic acids alter milk fatty acid composition and inhibit milk fat secretion in dairy cows. J. Nutr. 129:1579-1584.

Cochran, R. C., D. C. Adams, J. D. Wallace, and M. L. Galyean. 1986. Predicting the digestibility of different diets with internal markers: Evaluation of four potential markers. J. Anim. Sci. 63:1476-1483.

Drackley, J. K. 1999. ADSA Foundation Scholar Award. Biology of dairy cows during the transition period: The final frontier? J. Dairy Sci. 82:2259-2273.

Goering, H. K., and P. J. Van Soest. 1970. Forage Fiber Analysis (Apparatus, Reagents, Procedures, and Some Applications). Agricultural Handbook no. 379. Agricultural Research Service-USDA, Washington, DC.

Hach, C. C., B. K. Bowden, A. B. Lopelove, and S. V. Brayton. 1987. More powerful peroxide Kjeldahl digestion method. J. Assoc. Off. Anal. Chem. 70:783-787.

Hara, A., and N. S. Radin. 1978. Lipid extraction of tissues with a low-toxicity solvent. Anal. Biochem. 90:420-426.

Harvatine, K. J., Y. R. Boisclair, and D. E. Bauman. 2009a. Recent advances in the regulation of milk fat synthesis. Animal 3:40-54. 
Harvatine, K. J., J. W. Perfield II, and D. E. Bauman. 2009b. Expression of enzymes and key regulators of lipid synthesis is upregulated in adipose tissue during CLA-induced milk fat depression in dairy cows. J. Nutr. 139:849-854.

Jenkins, T. C., V. Fellner, and R. K. McGuffey. 2003. Monensin by fat interactions on trans fatty acids in cultures of mixed ruminal microbes grown in continuous fermenters fed corn or barley. J. Dairy Sci. 86:324-330.

Karkalas, J. 1985. An improved enzymatic method for the determination of native and modified starch. J. Sci. Food Agric. 36:10191027.

Lascano, G. J., M. Alende, L. E. Koch, and T. C. Jenkins. 2016. Changes in fermentation and biohydrogenation intermediates in continuous cultures fed low and high levels of fat with increasing rates of starch degradability. J. Dairy Sci. 99:6334-6341.

Maldini, G., and M. S. Allen. 2018. Temporal effects of ruminal propionic acid infusion on feeding behavior of Holstein cows in the postpartum period. J. Dairy Sci. 101:3077-3084.

McCarthy, M. M., T. Yasui, C. M. Ryan, G. D. Mechor, and T. R. Overton. 2015a. Performance of early-lactation dairy cows as affected by dietary starch and monensin supplementation. J. Dairy Sci. 98:3335-3350.

McCarthy, M. M., T. Yasui, C. M. Ryan, S. H. Pelton, G. D. Mechor, and T. R. Overton. 2015b. Metabolism of early-lactation dairy cows as affected by dietary starch and monensin supplementation. J. Dairy Sci. 98:3351-3365.

Mertens, D. R. 2002. Gravimetric determination of amylase-treated neutral detergent fiber in feeds using refluxing in beakers or crucibles: Collaborative study. J. AOAC Int. 85:1217-1240.

Mohammed, R., J. Kennelly, J. Kramer, K. Beauchemin, C. Stanton, and J. Murphy. 2010. Effect of grain type and processing method on rumen fermentation and milk rumenic acid production. Animal 4:1425-1444.

NRC. 2001. Nutrient Requirements of Dairy Cattle. 7th rev. ed. Natl. Acad. Press, Washington, DC.

Oba, M., and M. S. Allen. 2003a. Effects of corn grain conservation method on feeding behavior and productivity of lactating dairy cows at two dietary starch concentrations. J. Dairy Sci. 86:174183.

Oba, M., and M. S. Allen. 2003b. Dose-response effects of intrauminal infusion of propionate on feeding behavior of lactating cows in early or midlactation. J. Dairy Sci. 86:2922-2931.

Oba, M., and M. S. Allen. 2003c. Effects of corn grain conservation method on ruminal digestion kinetics for lactating dairy cows at two dietary starch concentrations. J. Dairy Sci. 86:184-194.

Piantoni, P., C. M. Ylioja, and M. S. Allen. 2015. Feed intake is related to changes in plasma nonesterified fatty acid concentration and hepatic acetyl CoA content following feeding in lactating dairy cows. J. Dairy Sci. 98:6839-6847.

Rabelo, E., R. L. Rezende, S. J. Bertics, and R. R. Grummer. 2003. Effects of transition diets varying in dietary energy density on lactation performance and ruminal parameters of dairy cows. J. Dairy Sci. 86:916-925

Rico, D. E., and K. J. Harvatine. 2013. Induction of and recovery from milk fat depression occurs progressively in dairy cows switched between diets that differ in fiber and oil concentration. J. Dairy Sci. 96:6621-6630.

Wildman, E. E., G. M. Jones, P. E. Wagner, R. L. Boman, H. F. Troutt Jr., and T. N. Lesch. 1982. A dairy cow body condition scoring system and its relationship to selected production characteristics. J. Dairy Sci. 65:495-501. 